\title{
Finding a point of reference to inspire a sustainability consciousness
}

\section{Maree Stansfield}

\begin{abstract}
Maree (Ree) is a researcher at the New Zealand School of Tourism. Her research is focused on how to inspire and facilitate sustainability consciousness and uptake in tourism, hospitality and education.
\end{abstract}

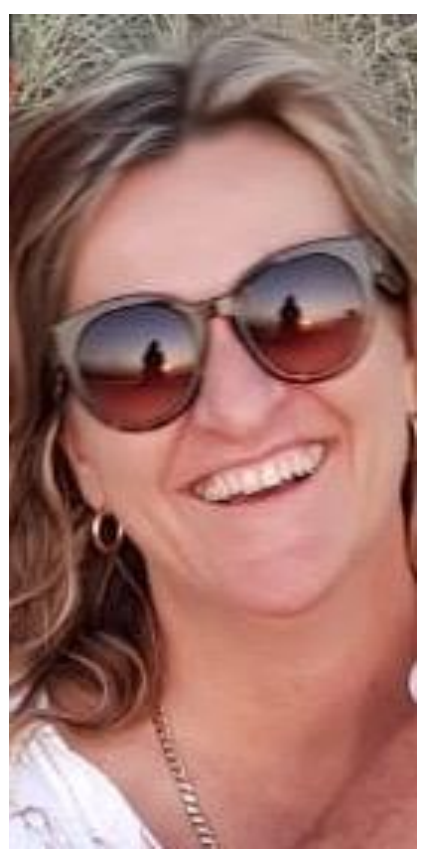

An educated workforce armed with sustainability-savvy worldviews, competencies and actions to counter our industry's waste output and resource use are assets for future businesses poised to respond to the sustainability call. The newcomer workforce released into industry every year offer hope, and a space to intervene and inject change. This article reports findings on a study designed to acquire the knowledge needed to inspire sustainability consciousness in staff and students at a hospitality and tourism tertiary education facility. It was encouraging to discover that the people who chose to participate in the study possessed promising skills valuable in the move towards sustainability.

This article reports on Phase 1 of a three-phase study with the final goal of imbedding sustainability practice and consciousness into the tertiary education research site. The study responds to the industry's lack of sustainability education and the workplace demand for this knowledge [1]. Frameworks to help progress sustainable change require settings in which to test and refine their design and worth; places of education have been recommended [2].

Phase 1 responds to research recommendations (e.g. [3]) and considers an individual's sustainability-focused worldview, competency level and selfreported actions. As such, a questionnaire was tailored to identify a snapshot of the research participants' ideas and actions around sustainability. The findings provide information to help prepare the design of Phase 2 and to plan for change.

The findings detail four themes that divide the respondents into four groups according to the traits they exhibited. The range of skill sets now identified can be tapped into, enhanced, encouraged and stimulated in the next two phases.

Theme 1 participants are value-laden and action-orientated collaborators who envision the future based on a reasonable knowledge base. They subscribe to intergenerational equity, understand cause and effect and will act in accord with an internal locus of control. These individuals have the capacity to reflect, process ideas and offer solutions. They offer promise as leaders and knowledge sharers.

Theme 2 individuals want to be involved, find solutions, and aspire to be part of a progressive sustainability group. Although they showcase unexpected and at times undeveloped thought processing in the face of sustainability- 
related issues, they are eager, outside-the-box thinkers. Armed with accurate knowledge, Theme 2's people will generate buy-in amongst peers with their enthusiasm.

The people that make up Theme 3 respond to influence and stimulus; they can be led and will likely follow. Given the right information, tools and inspiration they represent a good-sized group that may buy-in to positive change. The findings indicate they can make the transition towards sustainability thinking if supported with some well-formed narratives and resources.

Theme 4 is represented by people who appear disinterested in sustainability. They exhibit an external locus of control and do not contribute beyond the bare minimum. The follow-up research project (Phase 2) will be created to ignite buy-in among this group, and to inspire and educate them, in order to foster them as better informed and active individuals.

The research team now have a reference point from which to move to Phase 2. The focus groups in Phase 2 will include the participants from Phase 1. The purpose will be to engage the people involved, inform them of Phase 1 findings, and encourage them to offer ideas for crafting a pathway towards sustainability uptake at the research site. Previous research tells us that engaging people to inspire buy-in and providing a space where they become the key players in crafting a new way forward are key factors in a move towards a sustainability-centric future [4]. Critically, the student participants will then enter the hospitality and tourism workforce armed with a sustainability consciousness that can instigate positive change.

\section{Corresponding author}

Maree Stansfield can be contacted at: reestansfield@nzschooloftourism.co.nz

\section{References}

(1) Sloan, P.; Legrand, W.; Chen, J. Sustainability in the Hospitality Industry: Principles of Sustainable Operations, 2nd ed.; Routledge: London, 2013.

(2) Wiek, A.; Withycombe, L.; Redman, C. L. Key Competencies in Sustainability: A Reference Framework for Academic Program Development. Sustainability Science 2011, 6 (2), 203-218. https://doi.org/10.1007/s11625-011-0132-6

(3) Dunlap, R. E.; Van Liere, K. D. The 'New Environmental Paradigm'. The Journal of Environmental Education 1978, 9 (4), 10-19.

(4) Shephard, K. Researching Higher Education for Sustainable Development: Plan A, Plan B and Moving Beyond Thought-Limiting Clichés. In Sustainable Development Research in the Asia-Pacific Region: Education, Cities, Infrastructure and Buildings; Leal Filho, W., Rogers, J., Iyer-Raniga, U., Eds.; Springer International: Cham, Switzerland, 2018, pp 17-30. https://doi.org/10.1007/978-3-319-73293-0 